\title{
Gas-Phase Interactions as Sources of Contamination in Solar Silicon
}

\author{
Y.V. METELEVA-FISCHER, A.J. BÖTTGER, W.G. SLOOF, and B. KRAAIJVELD
}

Avoiding contamination of silicon for solar cells during high-temperature processing steps is a key issue. Contamination of silicon via direct contact due to diffusion processes has been recognized. Here, it is shown that interactions with the gas phase also are a potential source of contamination. Thermodynamic calculations performed for a temperature range of $373 \mathrm{~K}$ to $1873 \mathrm{~K}\left(100{ }^{\circ} \mathrm{C}\right.$ to $\left.1600{ }^{\circ} \mathrm{C}\right)$ and total pressure of $10 \mathrm{kPa}$ predict the formation of volatile species that are harmful for photovoltaic properties. Volatile species form due to graphitemoisture interaction and the interaction of this gas mixture with compounds commonly present in silicon production units: graphite, quartz, alumina, boron nitride, and iron. The results of the calculations are supported by the data of the surface contamination of exposed graphite furnace parts.

DOI: $10.1007 / \mathrm{s} 40553-014-0017-6$

(C) The Minerals, Metals \& Materials Society and ASM International 2014

\section{INTRODUCTION}

COnventional production of solar silicon comprises ingot growing and wafer sawing as last process steps. ${ }^{[1]}$ This process has a low throughput due to batch technology and leads to more than 50 pct silicon material loss in the entire production chain. ${ }^{[2]}$ These drawbacks can be avoided using ribbon-growth-onsubstrate (RGS) technology. The RGS technology offers high throughput by using a process of continuous casting of silicon wafer with a speed of about 1 wafer per second and almost no material loss because no cutting and sawing is needed. Moreover, significant energy consumption savings are realized due to the absence of heating-cooling cycles. ${ }^{[3]}$ However, contamination of silicon occurs during continuous casting because of the direct contact of silicon with parts (substrates, crucible) in the casting facility, as well as through the interaction with the gas ambient. In a conventional silicon crystal growth process, gas interactions are considered to be triggered by the formation of $\mathrm{SiO}$ gas due to the diffusion of oxygen from the quartz crucible through the silicon nitride coating to silicon. ${ }^{[4,5]}$ The transport of $\mathrm{SiO}$ by the argon flow to graphite parts and the subsequent reaction of $\mathrm{SiO}$ with graphite leads to the formation of $\mathrm{CO}$ and $\mathrm{SiC}$. Convectional or diffusional transport of the produced $\mathrm{CO}$ to the silicon interface causes the contamination of silicon by carbon. ${ }^{[4,5]}$ Indeed, it has been shown that the

Y.V. METELEVA-FISCHER, Postdoctoral Researcher, is with the Materials innovation institute M2i, Mekelweg 2, 2628 CD Delft, The Netherlands. Contact e-mail: y.meteleva-fischer@m2i.nl, ymfischer@ gmail.com A.J. BÖTTGER and W.G. SLOOF, Associate Professors, are with the Delft University of Technology, Mekelweg 2, 2628 CD Delft, The Netherlands. B. KRAAIJVELD, COO, is with RGS Development B.V., Bijlestaal 54, 1754 PW Broek op Langedijk, The Netherlands.

Manuscript submitted October 28, 2013.

Article published online May 1, 2014 increase of argon flow increases the $\mathrm{SiO}$ evaporation rate and therefore enhances the formation of $\mathrm{CO}^{[6]}$ Modeling of carbon contamination in an argon flow ${ }^{[4]}$ results in much smaller impurity levels (by factor 2) than the experimentally measured values. Such a large difference points to the presence of another source of carbon contamination (from the gas phase), as will be shown in this article.

Outgassing of materials used in silicon production units is barely considered yet as a source of contamination of silicon. In the RGS process, a graphite crucible is used instead of a quartz crucible and no flow is present; still, contamination by both oxygen and carbon occurs. The major difference between the ingot growing techniques and the RGS process is the amount of graphite material present as construction materials, moving parts, and isolation. Outgassing of graphite-based materials was studied experimentally with a focus on space and nuclear applications: ${ }^{[7,8]} 99$ pct of the outgas was removed in vacuum during 86 hours at $1773 \mathrm{~K}$ $\left(1500{ }^{\circ} \mathrm{C}\right)$, and it took up to 1200 hours at a lower temperature of $1073 \mathrm{~K}\left(800{ }^{\circ} \mathrm{C}\right) .{ }^{[7]}$ Thus, the composition of the gas phase in silicon production units may be dominated by outgassing of the constituting materials, such as bulky graphite as the main construction material and boron nitride, alumina, and quartz as electrical insulator and protection materials. In this work, potential sources of silicon contamination are identified using thermodynamic calculations of graphite outgassing and subsequent interactions of the resulting gas phase with materials commonly present in the RGS silicon casting unit.

\section{EXPERIMENTAL}

Materials of interest for the calculation were selected based on common materials used in an RGS machine as well as in any silicon ingot growing facility. Graphite 
was used as lining insulation and crucible material, while quartz served as crucible and electric insulator material. Boron nitride served as an electric insulation material and alumina as thermocouple protection, construction, and insulation material. Iron parts ensured the conveyer movement and were cooled by water.

Moisture is an inevitable contaminant, which absorbs when exposed to air and stems from the aforementioned materials during heating. Water molecules adsorbed in pores ${ }^{[9]}$ will be released at high temperatures. ${ }^{[10]}$ Since graphite is mainly applied in the casting facility and strongly adsorbs water vapor, first, the equilibrium gasphase composition due to graphite-moisture interactions was calculated. Next, the reaction products were predicted that may occur when this gas phase is in equilibrium with the aforementioned materials including silicon. In the calculations, $1 \mathrm{~mol}$ of each material was taken and $<10^{-3} \mathrm{~mol}$ for the material consumption was considered in all cases.

These calculations of equilibrium gas composition in a graphite-moisture ambient were carried out using FactSage $6.3^{*}$ software ${ }^{[11]}$ for temperatures in the range of

*FactSage is a trademark of thermochemical software and database package developed jointly between Thermfact/CRCT, Montreal, Canada, and GTT-Technologies, Aachen, Germany.

$373 \mathrm{~K}$ to $1873 \mathrm{~K}\left(100{ }^{\circ} \mathrm{C}\right.$ to $\left.1600{ }^{\circ} \mathrm{C}\right)$ and total pressure of $100 \mathrm{kPa}$, which is commonly encountered in industrial casting facilities. The gas phase contained mainly argon, which is inert in the temperature range considered. The initial partial pressure of water was varied from 1 to $1 \times 10^{4} \mathrm{~Pa}$. Since the partial pressure of initial water, $p\left(\mathrm{H}_{2} \mathrm{O}_{\text {initial }}\right)$, is much lower than that of argon, it can be considered as a diluted gas mixture. Thus, the partial pressure of water at a constant total pressure $P$ is proportional to its mole fraction. The equilibrium module of the FactSage software was used to calculate the global minimum of the Gibbs free energy at a constant temperature and total pressure for the system containing reagents (graphite and moisture) and the possible products (as previously discussed). In total, 242 species were included. Plasma ions were discarded and the no. of carbon atoms in organic products was limited to 12 (a higher number does not affect the outcome of the calculations). The database FactPS of the FactSage software was used, because it contains the thermodynamic data of all included compounds. The graphite phase remained unchanged in the temperature range considered; thus, all reactions were controlled by the partial pressure of water. Here, $1 \mathrm{~mol}$ of graphite was used; however, for the conditions applied, the equilibrium was independent of the amount of graphite.

The equilibrium composition calculations showed a possible formation of 40 gaseous species when the cutoff limit of the FactSage software was $1 \times 10^{-75} \mathrm{~mol}$. However, the experimental limit to record gaseous species was determined by the mass spectrometer used, which was estimated to be $1 \times 10^{-4} \mathrm{~Pa}$. The compounds whose partial pressure, $p$ (gas), did not exceed this value will not be discussed here.
The concentration of contaminants in RGS silicon wafers is very small (ppb to ppm range), which makes it difficult to determine with high accuracy. However, even very small concentrations of metal diminish the photovoltaic performance of silicon. ${ }^{[12]}$ The graphite parts used for insulation in the RGS machine were made of graphite purified for photovoltaic application (SIGRATHERM**

**SIGRATHERM is a registered trademark of the SGL Group companies, Wiesbaden, Germany.

rigid felts), which contained $<1 \mathrm{ppm}$ of impurities in total before use according to the specification of the supplier (SGL Carbon Group, Wiesbaden, Germany). During the casting of silicon wafers, these graphite parts were exposed to the machine's ambient for a longer time and accumulated contamination from the gas phase. Such graphite parts, both virgin and contaminated, were provided by RGS Development B.V. (Oudkarspel, Netherlands) and were analyzed using X-ray fluorescence (XRF) spectroscopy with a PANalytical Axios ${ }^{\mathrm{mAX}}$ WD-XRF spectrometer (PANalytical B.V., Almelo, The Netherlands). Data evaluation was done with Super Q5.0i/Omnian software (PANalytical B.V., Almelo, The Netherlands) considering carbon as the matrix element. While the virgin graphite did not show any metals present, which confirms the supplier's specification (the XRF detection limit is about $1 \mathrm{ppm}$ ), the XRF analysis of the contaminated graphite isolation showed the presence of traces of the following elements: oxygen $(\sim 8 \mathrm{pct})$, silicon (500 to $850 \mathrm{ppmw})$, iron ( $\leq 500 \mathrm{ppmw})$, aluminum ( $\leq 350 \mathrm{ppmw}$ ), calcium and magnesium (both $\leq 200 \mathrm{ppmw}$ ), and chlorine ( $\leq 150 \mathrm{ppmw})$. The reproducibility of the composition analysis for different samples is within 15 pct. The correct quantification of the XRF data is complicated by the inhomogeneity of the sample, as the contamination is located in the 1- to $2-\mu \mathrm{m}$ surface layer. This was confirmed by laser ablation-mass spectroscopy (LA-MS). With the aim to identify the sources of the contamination by these metals, the thermodynamic equilibrium calculations were performed with the following materials of the parts in the RGS machine: silicon, quartz, alumina, boron nitride, and iron.

\section{RESULTS AND DISCUSSION}

\section{A. Thermodynamic Modeling of Graphite-Moisture Interactions}

Calculations of the equilibrium compositions show that about 40 different gaseous species may occur. Their partial pressure changes significantly with temperature. The calculated equilibrium composition for the initial water vapor pressure of $10 \mathrm{kPa}$ in the temperature range of $373 \mathrm{~K}$ to $1873 \mathrm{~K}\left(100{ }^{\circ} \mathrm{C}\right.$ to $\left.1600{ }^{\circ} \mathrm{C}\right)$ at a total pressure of $100 \mathrm{kPa}$ is presented in Figure 1. Five major gas species, $\mathrm{H}_{2} \mathrm{O}, \mathrm{CO}_{2}, \mathrm{CO}, \mathrm{H}_{2}$, and $\mathrm{CH}_{4}$, are in equilibrium below $1273 \mathrm{~K}\left(1000{ }^{\circ} \mathrm{C}\right)$. However, above $1273 \mathrm{~K}$ $\left(1000{ }^{\circ} \mathrm{C}\right)$, only significant amounts of $\mathrm{CO}$ and $\mathrm{H}_{2}$ remain. These results agree well with the data for outgassing 


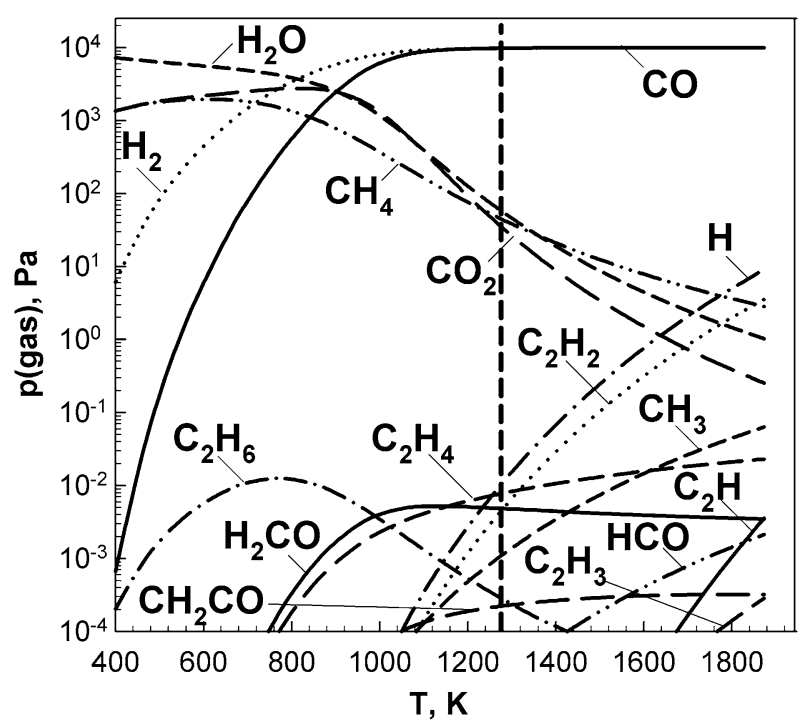

Fig. 1-Gas-phase composition of the graphite-moisture system at $p\left(\mathrm{H}_{2} \mathrm{O}_{\text {initial }}\right)=10 \mathrm{kPa}$.

of graphite of Craig ${ }^{[13]}$ and Shirasu et al. ${ }^{[8]}$ They recorded concentrations of $\mathrm{CO}$ and $\mathrm{H}_{2}$ in the outgassing of graphite and graphite-based materials as 25 to 50 times higher than other gaseous species above $1273 \mathrm{~K}\left(1000{ }^{\circ} \mathrm{C}\right)$.

The calculated values of partial pressures of gas products are the result of a superposition of many chemical reactions and are difficult to derive manually. It was found that the partial pressure of every gaseous product is directly proportional to the partial pressure of water in the range of 1 to $10^{4} \mathrm{~Pa}$ and depends only on temperature. Although the kinetics of the graphite oxidation has been studied, ${ }^{[14-16]}$ there is still no agreement on the nature of the reaction states and the rate-limiting step of the process. ${ }^{[16]}$

Below about $930 \mathrm{~K}\left(657^{\circ} \mathrm{C}\right)$, the oxidation of graphite by moisture results in $\mathrm{CO}_{2}$ and $\mathrm{CH}_{4}$ formation, and above this temperature, $\mathrm{CO}$ and $\mathrm{H}_{2}$ formation dominates (Figure 1). The equilibrium partial pressure of both $\mathrm{CO}_{2}$ and $\mathrm{CH}_{4}$ shows a peak-shaped dependence on temperature. The maximum partial pressure of $\mathrm{CH}_{4}$ is expected at $598 \mathrm{~K}\left(325^{\circ} \mathrm{C}\right)$, whereas the peak of $\mathrm{CO}_{2}$ formation is expected at $\sim 770 \mathrm{~K}\left(497{ }^{\circ} \mathrm{C}\right)$. Trace gases in amounts 6 to 7 orders of magnitude lower than $p\left(\mathrm{H}_{2} \mathrm{O}_{\text {initial }}\right)$ are predicted: $\mathrm{C}_{2} \mathrm{H}_{6}$ at $373 \mathrm{~K}$ to $1400 \mathrm{~K}\left(100^{\circ} \mathrm{C}\right.$ to $\left.1127^{\circ} \mathrm{C}\right)$; $\mathrm{C}_{2} \mathrm{H}_{4}$ and $\mathrm{H}_{2} \mathrm{CO}$ at $750 \mathrm{~K}$ to $1800 \mathrm{~K}\left(477^{\circ} \mathrm{C}\right.$ to $\left.1527{ }^{\circ} \mathrm{C}\right)$; and atomic hydrogen, $\mathrm{C}_{2} \mathrm{H}_{2}, \mathrm{CH}_{3}$, and $\mathrm{CH}_{2} \mathrm{CO}$ at $1050 \mathrm{~K}$ to $1800 \mathrm{~K}\left(777^{\circ} \mathrm{C}\right.$ to $\left.1527^{\circ} \mathrm{C}\right)$. Very small amounts of $\mathrm{HCO}$ at $1400 \mathrm{~K}$ to $1800 \mathrm{~K}\left(1127^{\circ} \mathrm{C}\right.$ to $\left.1527{ }^{\circ} \mathrm{C}\right), \mathrm{C}_{2} \mathrm{H}$ at $1670 \mathrm{~K}$ to $1800 \mathrm{~K}\left(1397{ }^{\circ} \mathrm{C}\right.$ to $\left.1527^{\circ} \mathrm{C}\right)$, and $\mathrm{C}_{2} \mathrm{H}_{3}$ at $1760 \mathrm{~K}$ to $1800 \mathrm{~K}\left(1487^{\circ} \mathrm{C}\right.$ to $\left.1527^{\circ} \mathrm{C}\right)$ can also be formed below $1200 \mathrm{~K} \quad\left(927^{\circ} \mathrm{C}\right)$. The partial pressure of $\mathrm{C}_{2} \mathrm{H}_{6}$ exhibits peak-shaped dependence on temperature. Other trace gaseous products show an exponential increase of their partial pressures with the rise in temperature.

\section{B. Interactions with Silicon}

The gas composition in the graphite-moisture system modeled previously is referred to as "system" in the

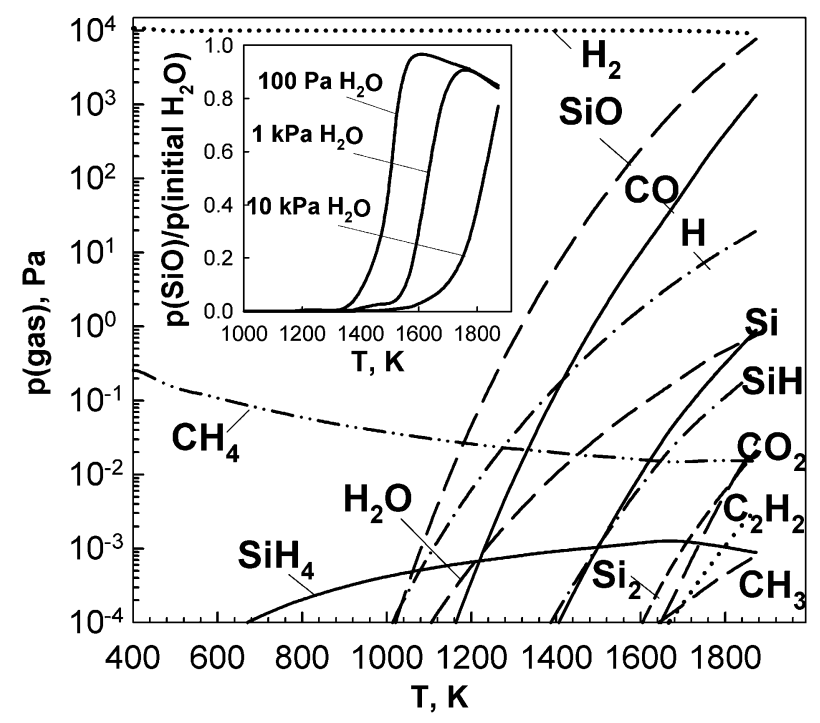

Fig. 2-Gas-phase composition of system with $\mathrm{Si}$ at $p\left(\mathrm{H}_{2} \mathrm{O}_{\text {initial }}\right)=$ $10 \mathrm{kPa} ; p(\mathrm{SiO})$ at different $p\left(\mathrm{H}_{2} \mathrm{O}_{\text {initial }}\right)$ (inset).

remainder of the article. The calculations show that a large part of the system gases reacts with silicon (Figure 2). All carbon- and oxygen-containing gases react with silicon at temperatures already below the melting point of silicon, which contributes to the carbon content in silicon wafer and the outer part of silicon ingots. ${ }^{[17]}$ As a result of silicon-system interactions, additional $\mathrm{H}_{2}$ and atomic hydrogen are produced; silicon-containing gases, $\mathrm{SiO}, \mathrm{SiH}, \mathrm{SiH}_{4}, \mathrm{Si}$, and $\mathrm{Si}_{2}$, and solid $\mathrm{SiC}$ and $\mathrm{SiO}_{2}$ are formed. In the system without silicon (Figure 1), the partial pressure of hydrogen increases with temperature rise and reaches values close to the partial pressure of initial water above $\sim 1000 \mathrm{~K}\left(727^{\circ} \mathrm{C}\right)$, whereas in equilibrium with silicon, the partial pressure of hydrogen is almost equal to the partial pressure of initial water in the entire range of temperatures (Figure 2).

In the inset of Figure 2, the partial pressure of $\mathrm{SiO}$ divided by the partial pressure of initial water shows a nonlinear dependence on the partial pressure of initial water. With the increase in partial pressure of initial water, the temperature range of $\mathrm{SiO}$ formation shifts toward high temperatures.

The formed $\mathrm{SiC}, \mathrm{SiO}_{2}$, and $\mathrm{SiO}$ contribute to silicon contamination by carbon and oxygen, whereas $\mathrm{SiO}$ is transported to constructional parts of the machine and reacts, forming $\mathrm{CO}$ and $\mathrm{SiC} .{ }^{[4-6]}$ This can explain the presence of silicon traces on graphite isolation. Moisture plays a key role in the volatilization of graphite and silicon, so that both silicon consumption and contamination depend on the initial partial pressure of water. Thus, if silicon is not in contact with the ambient during outbaking of the graphite, its contamination can be substantially reduced.

\section{Interactions with Quartz}

When system gases are in contact with a quartz surface, practically no reactions take place below 


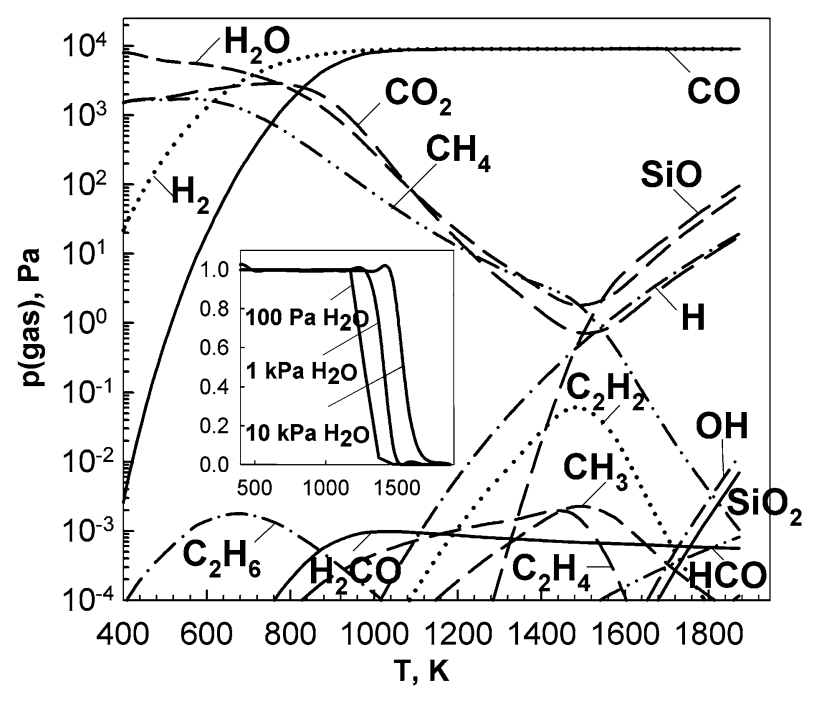

Fig. 3 - Gas-phase composition of system with $\mathrm{SiO}_{2}$ at $p\left(\mathrm{H}_{2} \mathrm{O}_{\text {initial }}\right)=$ $10 \mathrm{kPa}$; ratio of $p\left(\mathrm{CH}_{4}\right)$ in system with and without $\mathrm{SiO}_{2}$ at different $p\left(\mathrm{H}_{2} \mathrm{O}_{\text {initial }}\right)$ (inset).

$1200 \mathrm{~K}\left(927^{\circ} \mathrm{C}\right)$, as shown in Figure 3. Noticeable differences in the gas composition occur above $1200 \mathrm{~K}$ $\left(927^{\circ} \mathrm{C}\right.$ ), where $\mathrm{CH}_{4}, \mathrm{C}_{2} \mathrm{H}_{2}, \mathrm{CH}_{3}, \mathrm{C}_{2} \mathrm{H}_{4}$, and $\mathrm{HCO}$ are consumed. In the inset of Figure 3, the ratio between the partial pressure of $\mathrm{CH}_{4}$ with and without $\mathrm{SiO}_{2}$ shows a significant consumption of the gas above $1200 \mathrm{~K}$ $\left(927^{\circ} \mathrm{C}\right)$; the start of the gas consumption is shifted toward lower temperatures if the partial pressure of initial water is lowered. At the same time, above $1500 \mathrm{~K}$ $\left(1227^{\circ} \mathrm{C}\right)$, the partial pressures of water and $\mathrm{CO}_{2}$ increase. Pure graphite can be formed due to interaction between quartz and the calculated gas phase at high initial partial pressure of water $(10 \mathrm{kPa})$. No $\mathrm{SiC}$ is formed from quartz at any of the conditions used. This is in contrast to the interaction of the system gases with silicon, as discussed previously.

\section{Interactions with Alumina}

Alumina (ALSINT 99.7, Morgan Technical Ceramics Haldenwanger, Waldkraiburg, Germany) is a common material in isolation constructions due to its excellent thermal stability and low electric conductivity. Alumina contains 0.3 pct of binder, which is a mixture of $\mathrm{SiO}_{2}$ and $\mathrm{MgO}$. Thermodynamic calculations show that the interaction of system gases with alumina could result in the production of gases that are harmful for the photovoltaic properties of silicon. It is important to mention that in the calculations, the binder is fully exposed to the gas phase; in practice, however, only a small part of it can be found on the surface. Nevertheless, it shows the general effect of the interactions with the system gases.

The calculation of interactions of the system gas phase with alumina shows almost no changes in the gas composition below $1200 \mathrm{~K}\left(927^{\circ} \mathrm{C}\right)$. Above this temperature, the binder material starts to produce volatile species, such as $\mathrm{SiO}, \mathrm{SiO}_{2}, \mathrm{Mg}, \mathrm{MgH}$, and $\mathrm{MgOH}$ (Figure 4). Above $1400 \mathrm{~K}\left(1127^{\circ} \mathrm{C}\right)$, the formation of

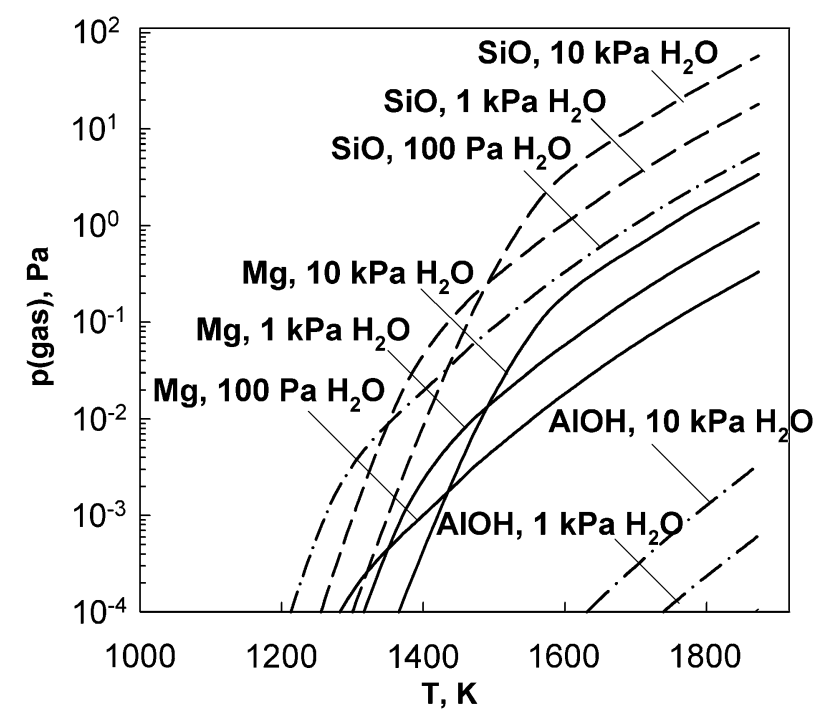

Fig. 4-Partial pressure of $\mathrm{SiO}, \mathrm{Mg}$, and $\mathrm{AlOH}$ in system with alumina (with binder).

gaseous $\mathrm{Al}, \mathrm{AlH}, \mathrm{AlOH}$, and $\mathrm{AlO}_{2} \mathrm{H}$ is predicted. Figure 4 demonstrates that $\mathrm{SiO}, \mathrm{Mg}$, and $\mathrm{AlOH}$ are the most prominent gas contaminants, all showing a nonlinear dependence on moisture content. It has been shown that at much higher moisture content, even higher amounts of volatile species can be produced due to a formation of $\mathrm{Al}(\mathrm{OH})_{3}$ gas, which results in measurable weight losses of alumina. ${ }^{[18]}$

Gaseous $\mathrm{Mg}$ and $\mathrm{AlOH}$ are the sources of silicon contamination by $\mathrm{Mg}$ and $\mathrm{Al}$. Formation of solid graphite due to the interaction of system gases with alumina is predicted at all partial pressures of initial water; this graphite dust also could be a source of contamination of the silicon surface. In order to avoid such contamination, a bake-out procedure for alumina parts is recommended in order to remove the binder from the surface. In addition, the alumina parts heated to temperatures above $1400 \mathrm{~K}\left(1127^{\circ} \mathrm{C}\right)$ should have no direct contact with the gas phase exposed to silicon to avoid its contamination by $\mathrm{Al}$.

\section{E. Interactions with Boron Nitride}

Boron nitride is often present as an insulator material in furnace constructions. It contains up to $0.5 \mathrm{wt}$ pct of calcium borate as a binder depending on its grade. Equilibrium calculations showed that $\mathrm{BN}$ is sensitive to moisture and can be oxidized by system gases. Many gas species form if the system gases are in contact with BN and binder (Figure 5), the most volatile among them being $\mathrm{N}_{2}, \mathrm{NH}_{3}, \mathrm{HBO}, \mathrm{HCN}, \mathrm{HBO}_{2}, \mathrm{BO}, \mathrm{B}_{2} \mathrm{O}_{2}, \mathrm{Ca}$, $\mathrm{BH}_{2}, \mathrm{~B}_{2} \mathrm{O}_{3}, \mathrm{BH}_{3}$, and $\mathrm{CaH}$. These species interact with the solidifying silicon: nitrogen causes bubbles and pores in solidifying silicon, boron containing gas products results in an elevated level of boron, and the dissolution of calcium in liquid silicon can reduce the quality of the final silicon. Moreover, ammonium is predicted to be formed and could be transported to the cold iron parts, causing its degradation. The use of boron nitride in 


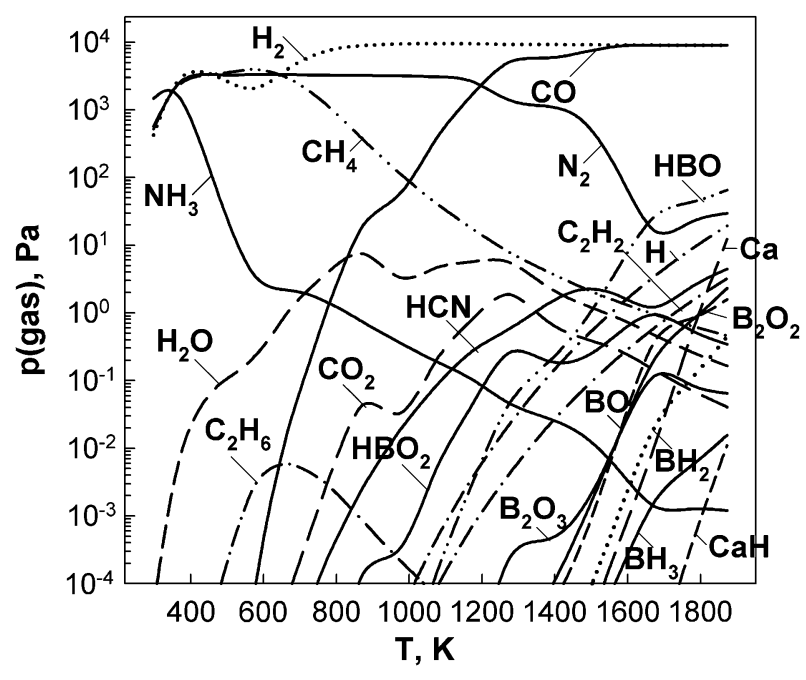

Fig. 5- Gas-phase composition of system with BN (with binder) at $p\left(\mathrm{H}_{2} \mathrm{O}_{\text {initial }}\right)=10 \mathrm{kPa}$.

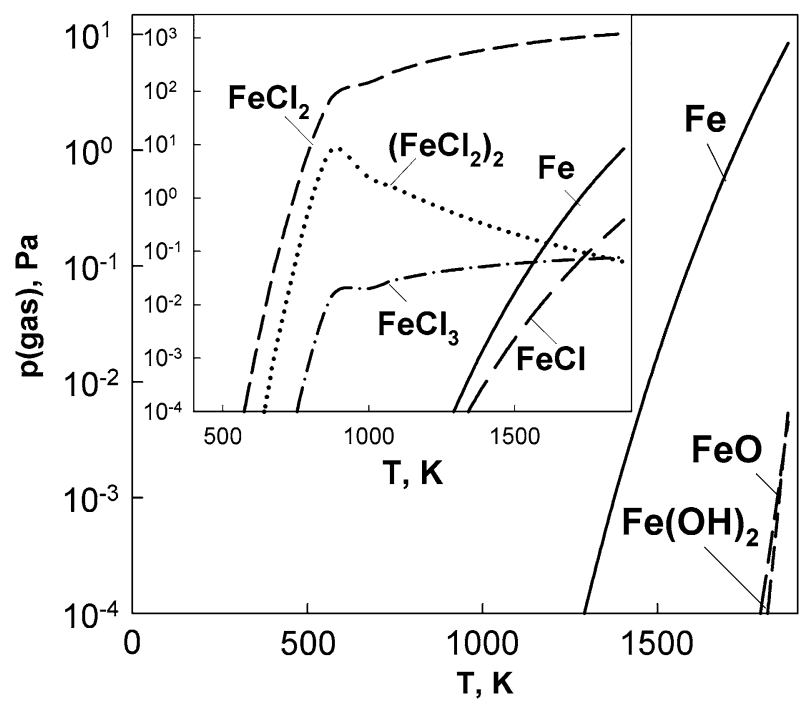

Fig. 6-Partial pressures of Fe-containing gases in system with $\mathrm{Fe}$ at $p\left(\mathrm{H}_{2} \mathrm{O}_{\text {initial }}\right)=10^{4} \mathrm{~Pa}$, and the same system with $10^{3} \mathrm{~Pa}$ of $\mathrm{HCl}$ (inset).

silicon production units should be avoided, since it pollutes the gas phase already at low temperatures $\left(>800 \mathrm{~K}\left(527^{\circ} \mathrm{C}\right)\right)$.

\section{F. Interactions with Iron}

Although the iron parts in the RGS machine are intensively cooled, they also could be in contact with the gas ambient and react. The equilibrium calculations have shown that only above $1300 \mathrm{~K}\left(1027^{\circ} \mathrm{C}\right)$ does the formation of gaseous $\mathrm{Fe}, \mathrm{FeO}$, and $\mathrm{Fe}(\mathrm{OH})_{2}$ occur (Figure 6). Since the iron parts are cooled by water, they will not reach this temperature and, thus, cannot cause Fe contamination. However, traces of iron were detected on the graphite isolation. The graphite construction parts of the RGS facility that were mechanically machined were usually consequently washed with a $\mathrm{HCl}$ solution. Assuming that some $\mathrm{HCl}$ could remain in graphite after washing and drying, $10^{3} \mathrm{~Pa}$ of $\mathrm{HCl}$ was added to the equilibrium calculations.

In the inset to Figure 6, the partial pressures of gas products are presented that are formed if $\mathrm{HCl}$ is present in the gas ambient. It is shown that various iron chlorides are predicted, and $\mathrm{FeCl}_{2}$ could already be formed at $\sim 600 \mathrm{~K}\left(327^{\circ} \mathrm{C}\right)$. Although the iron parts are water cooled, it seems to be difficult to ensure that their temperature remains below this limit. This could be the possible source of iron contamination in silicon casting facilities and would explain the detection of iron traces on graphite isolation.

\section{CONCLUDING REMARKS}

Modeling of the gas-phase composition allows for prediction of the potential gas-phase contaminants of solar grade silicon. Interactions of graphite with adsorbed moisture result in a complex gas mixture. These gases cause contamination of silicon by carbon and oxygen. This gas mixture also interacts with alumina and boron nitride present in furnaces, thereby forming volatile species that are a source of aluminum, magnesium, boron, and calcium contamination of silicon. A source of iron contamination of silicon is proposed. It is recommended that boron nitride-based materials are only applied in a dry environment and that parts made of alumina should be avoided in the vicinity of silicon at temperatures above $1400 \mathrm{~K}$ $\left(1127^{\circ} \mathrm{C}\right)$. It has been demonstrated that silicon reacts with volatile species present in a furnace, leading to its low purity. The thermodynamic model presented here provides the means to choose the best materials for furnace parts in order to prevent (cross) contamination of silicon.

\section{ACKNOWLEDGMENTS}

This research was carried out under Project No. M71.7.12462 in the framework of the Research Program of the Materials innovation institute M2i (http:// www.m2i.nl). The authors are indebted to Ing. R.W.A. Hendrikx, Delft University of Technology, for the XRF measurements, and to Ing. H.C. de Waard, Utrecht University, for the LA-MS measurements.

\section{REFERENCES}

1. W. Zulehner, B. Neuer, and G. Rau: Ullmann's Encyclopedia of Industrial Chemistry, Wiley-VCH Verlag $\mathrm{GmbH} \& \mathrm{Co}$. KGaA, Weinheim, 2000, pp. 7-20.

2. D. Sarti and R. Einhaus: Sol. Energy Mater. Sol. Cells, 2002, vol. 72 , pp. $27-40$

3. A. Schönecker, A. Gutjahr, A. Burgers, S. Seren, and G. Hahn: Conference on Optoelectronics and Microelectronic Materials and Devices, ARCNN, Canberra, A.C.T., 2008, pp. 232-37.

4. D.E. Bornside, R.A. Brown, T. Fujiwara, H. Fujiwara, and T. Kubo: J. Electrochem. Soc., 1995, vol. 142, pp. 2790-2804. 
5. B. Gao, S. Nakano, and K. Kakimoto: J. Electrochem. Soc., 2010, vol. 157, pp. H153-H159.

6. Z. Li, L. Liu, W. Ma, and K. Kakimoto: J. Cryst. Growth, 2011, vol. 318, pp. 304-12.

7. C. Alexander: US Energy Research and Development Report, NTIS BMI-X-682, Batelle Columbus Laboratories, Columbus, 1977, pp. $1-20$.

8. Y. Shirasu, T. Matsuura, S. Yamanaka, and M. Miyake: Technol. Rep. Osaka Univ., 1991, vol. 41 (2064), pp. 297-303.

9. B.T. Kelly: Physics of Graphite, Applied Science Publishers, London, 1981.

10. A.J. Juhola, A.J. Palumbo, and S.B. Smith: JACS, 1952, vol. 74, pp. 61-64.

11. FactSage Software, http://www.factsage.com.
12. J.R. Davis, A. Rohatgi, R.H. Hopkins, P.D. Blais, P. Rai-Choudhury, J.R. McCormick, and H.C. Mollenkopf: IEEE Trans. Electron Dev., 1980, vol. 27 (4), pp. 677-87.

13. J.H. Craig: J. Vac. Sci. Technol., 1980, vol. 17 (6), pp. 1377-78.

14. E.S. Kim and C.H. Oh: Nucl. Technol., 2008, vol. 164 (2), pp. 278-85.

15. J.P. Blakely and L.G. Overholser: Carbon, 1965, vol. 3, pp. 269 75.

16. S. Ergun: Kinetics of the Reactions of Carbon Dioxide and Steam with Coke, U.S. Government Printing Office, Washington, DC, 1961, pp. 1-9.

17. Y.-Y. Teng, J.-C. Chen, C.-W. Lu, and C.-Y. Chen: J. Cryst. Growth, 2010, vol. 312, pp. 1282-90.

18. E.J. Opila and D.L. Myers: J. Am. Ceram. Soc., 2004, vol. 87 (9), pp. 1701-05. 